\title{
Preparation and Characterization of Water-Insoluble Gardenia Blue Pigment
}

\author{
Yakun Gao ${ }^{1,2,+}$, Jinchuan $X u^{3,+}{ }^{1}$, Guorong Liu ${ }^{1, *}{ }^{\mathbb{C}}$, Rong Nie ${ }^{1}$, Jiaojiao Duan ${ }^{1}$, Duoxia Xu ${ }^{1}$ \\ and Chengtao Wang ${ }^{1}$
}

check for updates

Citation: Gao, Y.; Xu, J.; Liu, G.; Nie, R.; Duan, J.; Xu, D.; Wang, C. Preparation and Characterization of Water-Insoluble Gardenia Blue Pigment. Materials 2021, 14, 6594. https://doi.org/10.3390/ma14216594

Academic Editors: Ricardo Branco, Filippo Berto and Yanxin Qiao

Received: 24 September 2021

Accepted: 29 October 2021

Published: 2 November 2021

Publisher's Note: MDPI stays neutral with regard to jurisdictional claims in published maps and institutional affiliations.

Copyright: (c) 2021 by the authors. Licensee MDPI, Basel, Switzerland. This article is an open access article distributed under the terms and conditions of the Creative Commons Attribution (CC BY) license (https:// creativecommons.org/licenses/by/ $4.0 /)$.
1 Beijing Advanced Innovation Center for Food Nutrition and Human Health, Beijing Engineering and Technology Research Center of Food Additives, Beijing Technology and Business University, Beijing 100048, China; gaoyakun2017@126.com (Y.G.); nierong@st.btbu.edu.cn (R.N.); duan.jiaojiao@st.btbu.edu.cn (J.D.); xuduoxia@th.btbu.edu.cn (D.X.); wangchengtao@th.btbu.edu.cn (C.W.)

2 Tianjin Heping District Market Supervision and Management Bureau, Tianjin 300041, China

3 School of Food Science and Engineering, South China University of Technology, Guangzhou 510640, China; jinchuanxu@foxmail.com

* Correspondence: liuguorong1983@126.com or liuguorong@th.btbu.edu.cn

+ Contributed equally to this work.

\begin{abstract}
Based on molecular simulations, the synthetic route of water-insoluble gardenia blue pigment was prepared by the reaction of genipin and L-Phenylalanine methyl ester hydrochloride. A highly purified pigment was obtained after extraction by chloroform and purification by silica gel column chromatography, and the value of color is up to 288. A study on the structural characteristics of the pigment was implemented with a scanning electron microscope, ultraviolet-visible spectrophotometer, Fourier transform infrared spectrometer, X-ray photoelectron spectrometer, and quatropde-time of flight mass spectrometer. The results showed that the surface of the pigment was largely smooth and spherical; The $\lambda_{\max }$ was $607 \mathrm{~nm}$, and the main functional groups include $\mathrm{O}-\mathrm{C}=\mathrm{O}$, $\mathrm{C}=\mathrm{O}, \mathrm{C}-\mathrm{N}, \mathrm{C}=\mathrm{C}, \mathrm{OH}$, and benzene ring; We detrained six different molecular weight and chemical structures of pigments and speculated the particular structures and formation mechanisms of three kinds of pigment, whose molecular weights are 690.1156, 720.1226, and 708.1246 Da, respectively. The pigment was only able to be dissolved in ethanol, methanol, acetone, ethyl acetate, and other strong polar organic solvents, but was not able to be dissolved in water, ethyl ether, petroleum ether, and other weak polar organic solvents. In terms of light and thermal stabilities, water-insoluble gardenia blue pigment is significantly better than water-soluble gardenia blue pigment $(p<0.05)$. When it is under direct light for 7 days or incubated at $80-120{ }^{\circ} \mathrm{C}$ for $24 \mathrm{~h}$, the pigment residual rates were $74.90,95.26,88.27$, and $87.72 \%$, respectively.
\end{abstract}

Keywords: gardenia blue pigment; water-insoluble; structure study; solubility study; stability study

\section{Introduction}

Pigments are widely used in food, medicine, maquillage, and other fields. Due to consumers' concern about the safety of synthetic pigments, the application of synthetic pigments was confined to a limited amount and natural pigments are used more frequently. The blue pigments used so far have mainly been synthetic and the food industry has expressed a growing interest in the use of natural blue pigment, especially for confectionery and pastries [1,2].

Gardenia blue pigment is a natural blue pigment of food additives [3]. The gardenia blue pigment is prepared by primary amine compounds and genipin from the hydrosylate of jasmine, which is colorful, safe, and has strong coloring power [4-7]. The gardenia blue pigment is always water-soluble, but it is unable to be dissolved in organic solvents and oil. These features limit the scope of application of the gardenia blue pigment. We also need some water-insoluble blue pigments for some necessary uses. Some researchers 
have already obtained some hydrophobic gardenia blue pigments through esterification or phospholipid acylation [8,9]. Some researchers studied the reaction mechanism of the hydrophobic gardenia blue pigment by its intermediates [10-13]. However, due to their high polymerization, the water-soluble and hydrophobic gardenia blue pigments have no exact structure and molecular weight [14-16].

The stability of the natural pigments is challenged due to light, heat, $\mathrm{pH}$, and the existence of metal ions or oxidants and reductants. Some researchers have studied the stability of water-soluble gardenia blue pigment, and they found that it was most unstable under light [17-19]. Others tried to improve the pigments' stability by adding color fixative, embedding and chemical modifying, and other different kinds of methods [20-23].

In order to widen the melting range and increase the stability of the gardenia blue pigment, we prepared a new kind of water-insoluble gardenia blue pigment and studied its structure and molecular weight preliminarily.

\section{Experiment}

\subsection{Materials}

Genipin (Linchuan zhixin Biotechnology Co., Ltd., Jiangxi, China). L-Phenylalanine methyl ester hydrochloride (Shanghai yuanye Biotechnology Co., Ltd., Shanghai, China). HPLC Acetonitrile $\left(\mathrm{CH}_{3} \mathrm{CN}\right)$ (Thermo Fisher Scientific (China) Co. Ltd., Shanghai, China). Stearyl chloride (Shanghai Macklin Biochemical Co., Ltd., Shanghai, China). Silica gel plate GF254, Glass chromatography jar, 200-300 mesh column chromatography silica gel (Qingdao Marine Chemical Co., Ltd., Shandong, China). Mineral ether (Beijing Chemical Works, Beijing, China). pH was adjusted by pH400 (Alalis, Shanghai, China). Color properties were performed on a CM-3600A Color tester (Konica Minolta, Tokyo, Japan). The microstructure was observed on an S-4800 field emission scanning electron microscope (FE-SEM) (Hitachi, Tokyo, Japan). Ultraviolet-visible (UV-vis) spectra were recorded on a UV-2450 spectrophotometer (Shimadzu Corporation, Kyoto, Japan). Functional groups were determined by AVATAR 370 Fourier transform infrared spectrometer (FTIR) (Thermo Nicolet Corporation, Madison, WI, USA) and Thermo esca lab 250Xi X-ray photoelectron spectrometer (XPS) (Thermo Fisher, Waltham, MA, USA). Liquid chromatography-mass spectrometry (LC-MS) analysis was performed on a $6530 \mathrm{LC}$ quatropde-time of flight mass spectrometer (Q-TOF LC/MS) (Agilent, California, CA, USA) using the following column: Inertsil ODS-4: $4.5 \mathrm{~mm} \times 150 \mathrm{~mm}, 5 \mu \mathrm{m}$ (Agilent, Philadelphia, PA, USA).

\subsection{Synthesis of Water-Insoluble Gardenia Blue Pigment}

To a solution of genipin $(2.5 \mathrm{mmol})$ and phenylalanine methyl ester hydrochloride $(3.0 \mathrm{mmol})$ in ethanol $(50 \mathrm{~mL}) \mathrm{NaOH}$ was added to $\mathrm{pH}=7.0$. After stirring for $25 \mathrm{~h}$ in aerobic condition at $60{ }^{\circ} \mathrm{C}$, the reaction mixture was distilled by a rotary evaporator and dried [11]. Then the reaction mixture was dispersed in ultrapure water and extracted with chloroform by 3 times and dried by sodium sulfate $\left(\mathrm{Na}_{2} \mathrm{SO}_{4}\right)$. Then the water-insoluble gardenia blue pigment was filtrated and concentrated by using silica gel column chromatography (ethyl acetate).

\subsection{UV-Vis Detection Method}

The water-insoluble gardenia blue pigment was dissolved by ethanol. The wavelength was $400-700 \mathrm{~nm}$.

\subsection{FTIR Detection Method}

Prepare the samples: The mass ratio of water-insoluble gardenia blue pigment and potassium chloride was 1:100, mixed them well and grind to 100 mesh. Then take a small amount of mixture to flake. Instrument parameters are as follows: DTGS detector, the spectrum range was $4000-400 \mathrm{~cm}^{-1}$ and the resolution ratio was $4 \mathrm{~cm}^{-1}$. Take off the water and air disturbance when scanning. 


\subsection{XPS Detection Method}

XPS was measured to determine the $\mathrm{C}, \mathrm{N}$, and $\mathrm{O}$ atoms of water-insoluble gardenia blue pigment at room temperature [24]. Instrument parameters: excitation source (Monochromatic $\mathrm{Al} \mathrm{K} \mathrm{K}_{\alpha}, \mathrm{HV}=1486.6 \mathrm{eV}$ ), the capacity was $150 \mathrm{~W}$, the beam spot was set at $650 \mu \mathrm{m}$, the measurement accuracy was set at $0.1 \mathrm{eV}$ and the vacuum reached $10^{-9} \mathrm{~Pa}$. We used $\mathrm{C} 1 \mathrm{~s}=284.8 \mathrm{eV}$ to correct charge.

\subsection{Thin Layer Chromatography (TLC)}

The developing agent was a chloroform/ethanol mixture $(22: 1, v / v)$. The $R_{\mathrm{f}}$ value of each pigment spot was calculated $[25,26]$.

\subsection{LC-MS Detection Method}

LC-MS was used to test the molecular mass of gardenia blue pigments. The instrument conditions were as follows, the sample temperature was kept at $25^{\circ} \mathrm{C}$, a $5.0 \mu \mathrm{L}$ sample was injected, the flow rate was $0.2 \mathrm{~mL} / \mathrm{min}, 2 \%$ methanoic acid-acetonitrile (A) and $2 \%$ methanoic acid-water (B) were the elution, the gradient of elution was: $0-40 \min (4 \%-100 \%$ A); $40-50 \min (100 \% \mathrm{~A}) ; 50-52 \mathrm{~min}(4-100 \% \mathrm{~A}) ; 52-60 \mathrm{~min}$ (4\% A). In addition, nitrogen gas was regarded as the nebulizer and auxiliary, which the desolvation temperature, pressure, and the flow rate was set at $300{ }^{\circ} \mathrm{C}, 35 \mathrm{psig}$, and $600 \mathrm{~L} / \mathrm{h}$. The argon gas was considered as the collision, and the energy was STE at $50 \mathrm{eV}$. The ESI capillary voltage was $4 \mathrm{kV}$. The mass scanned area was $m / z$ 100-1500.

\subsection{Solubility of the Pigment}

Soluble equal weight: The water-soluble and water-insoluble gardenia blue pigment were put into the different same volume solvents.

\subsection{The Light and Thermal Stabilities of the Pigments}

The light stability of the pigment was evaluated at different light conditions, sunlight (40,000 lux), lamplight (13,000 lux), room light (300 lux), and dark (control group). The thermal stability of the pigment was tested at different temperatures, $4^{\circ} \mathrm{C}, 40{ }^{\circ} \mathrm{C}, 60^{\circ} \mathrm{C}$, $80{ }^{\circ} \mathrm{C}, 100{ }^{\circ} \mathrm{C}, 120^{\circ} \mathrm{C}$, and room temperature $\left(25^{\circ} \mathrm{C}\right.$, control group). The samples were prepared by dissolving the water-soluble and water-insoluble gardenia blue pigment into ultrapure water and ethanol respectively, then adjusting the absorbance to 0.8 . The samples were put at each light condition for 7 days and each temperature for $24 \mathrm{~h}$ in glass test tubes and their color properties were identified [1].

\subsection{Calculation of Chromatism}

The color value of the pigment was evaluated by the following equation [27]: $E_{1 \mathrm{~cm}}^{1 \%}=\frac{A V}{100 \mathrm{~m}}$. In this equation, $E_{1 \mathrm{~cm}}^{1 \%}$ refers to the cuvette $(1 \mathrm{~cm} \times 1 \mathrm{~cm})$ and the concentration of the pigment solution is $1 \%$; $A$ means the absorbance at the maximum absorption wavelength $\left(\lambda_{\max }\right)$ of the pigment solution; $V(\mathrm{~mL})$ means the volume of the pigment solution; $m(\mathrm{~g})$ meansthe quality of the pigment. The color properties of the pigment were evaluated in terms of the CIE $L^{*} a^{*} b^{*}$ system [28-30]. Where $L^{*}$ is the brightness, $a^{*}$ is the green (-) or red (+), and $b^{*}$ represents the blue (-) or yellow (+). Chroma parameter (C) is defined as $C_{a b}^{*}=\sqrt{\mathrm{a}^{* 2}+\mathrm{b}^{* 2}}$, which is the color saturation of the pigments. The color difference $\left(\Delta L^{*}, \Delta a^{*}, \Delta b^{*}, \Delta C_{a b^{\prime}}^{*}\right.$ and $\left.\Delta E_{L a b}^{*}\right)$ was analyzed by using the following equations:

$$
\begin{aligned}
\Delta L^{*} & =L_{a f t e r}^{*}-L_{b e f o r e}^{*} \\
\Delta a^{*} & =a_{a f t e r}^{*}-a_{b e f o r e}^{*} \\
\Delta b^{*} & =b_{a f t e r}^{*}-b_{b e f o r e}^{*} \\
\Delta C_{a b}^{*} & =C_{a f t e r}^{*}-C_{b e f o r e}^{*}
\end{aligned}
$$




$$
\Delta E_{L a b}^{*}=\sqrt{\Delta L^{* 2}+\Delta a^{* 2}+\Delta b^{* 2}}
$$

\section{Results and Discussion}

\subsection{Establishment of Molecular Model of Water-Insoluble Gardenia Blue Pigments}

The simulation of the chemical structural formula of the intermediate products of the water-insoluble gardenia blue pigments was established by ChemBio3D Ultra11.0 (Figure 1). Then the lowest molecular energy conformation model was obtained by HyperChem Release 7.0, the lowest molecular energies of the intermediate product 1 and intermediate product 2 were $23.41 \mathrm{kcal} / \mathrm{mol}$ and $21.87 \mathrm{kcal} / \mathrm{mol}$ respectively. They are the most stable conformation.

(a)<smiles>COC(=O)C1=CN(C(Cc2ccccc2)C(C)=O)C=C2C(CO)=CC[C@H]12</smiles>

(b)<smiles>CC(=O)C(Cc1ccccc1)NC(=O)C1=CO[C@H](O)[C@]2(C)C(CO)=CC[C@H]12</smiles>

Figure 1. Simulation of the chemical structural formula of the intermediate product 1 (a) and intermediate product 2 (b) of the water-insoluble gardenia blue pigment.

\subsection{Purification of Water-Insoluble Gardenia Blue Pigment}

After extraction by chloroform and purification by silica gel column chromatography, the color value of water-insoluble gardenia blue pigment was up to 288 , which was 1.32 times higher than at the beginning (Table 1). It indicates that the purity of waterinsoluble gardenia blue pigment becomes higher. The pigment powder is in dark blue, and the pigment solution is in bright blue (ethanol as solvent). The $a^{*}(-)$ of water-insoluble gardenia blue pigment increased, it means the green chromaticity of the pigment reduced, the $b^{*}(-)$ of water-insoluble gardenia blue pigment reduced, it means the blue chromaticity of the pigment increased. These results indicate that water-insoluble gardenia blue pigment becomes bluer.

Table 1. The results of purification of the water-insoluble gardenia blue pigment.

\begin{tabular}{|c|c|c|c|c|c|c|}
\hline \multirow{2}{*}{ Purification } & \multirow{2}{*}{ Recovery Ratio } & \multirow{2}{*}{ Color Value } & \multirow{2}{*}{$\begin{array}{l}\text { Color Value } \\
\text { Increase }\end{array}$} & \multicolumn{3}{|c|}{ Color Properties } \\
\hline & & & & $L^{*}$ & $a^{*}$ & $b^{*}$ \\
\hline Synthesis & / & 124 & / & 79.32 & -25.47 & -14.18 \\
\hline Extraction & $75 \%$ & 219 & 0.77 & 78.99 & -24.67 & -15.99 \\
\hline $\begin{array}{c}\text { Silica gel } \\
\text { column } \\
\text { chromatography }\end{array}$ & $55 \%$ & 288 & 1.32 & 78.91 & -23.47 & -17.47 \\
\hline
\end{tabular}

\subsection{Microstructure of Water-Insoluble Gardenia Blue Pigment}

We studied the microstructure of water-insoluble gardenia blue pigment by FE-SEM by magnifying by 20,000. The results showed that the surface of the water-insoluble gardenia blue pigment was largely smooth and spherical (Figure 2). It makes the water-insoluble gardenia blue pigment hydrophobic. 


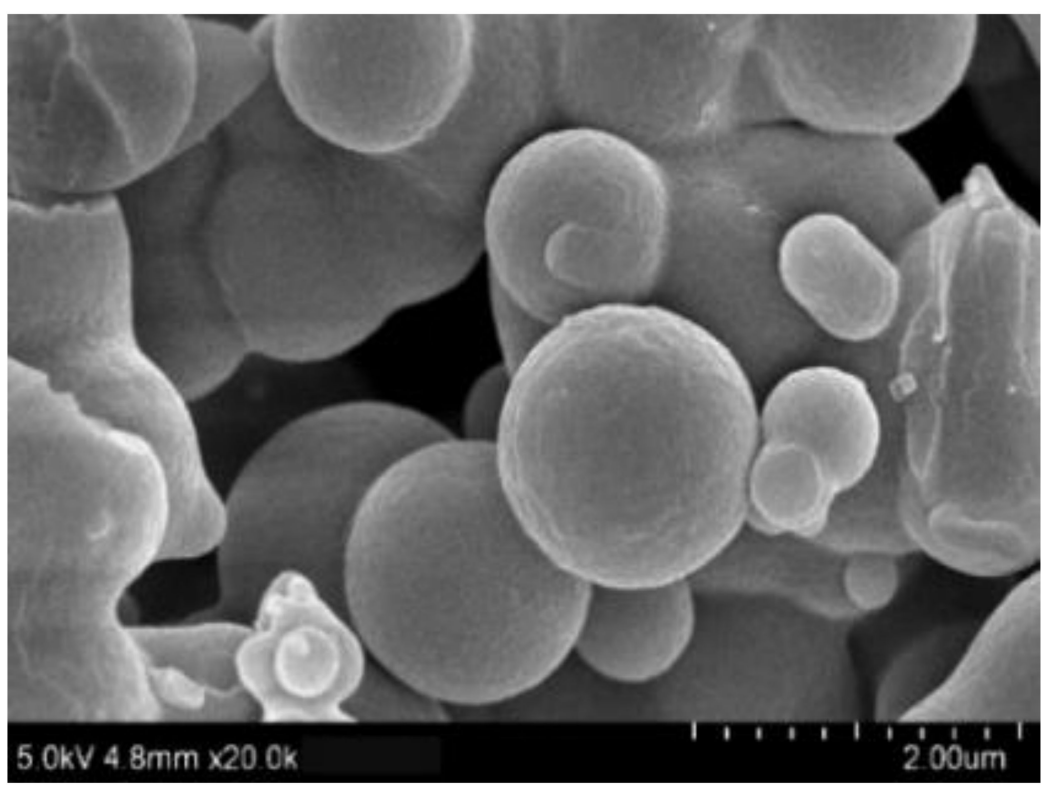

Figure 2. The SEM of water-insoluble gardenia blue pigment.

\subsection{UV Absorbance Wavelength of Water-Insoluble Gardenia Blue Pigment}

Next, we studied the characteristics of absorbance wavelength of gardenia blue pigments by UV-vis. The blue broad optical absorption band of the pigments is at wavelengths between 590 and $620 \mathrm{~nm}$. Figure 3 shows that the water-insoluble gardenia blue pigment has one sharp absorption peak at $607 \mathrm{~nm}\left(\lambda_{\max }\right)$. Masaaki TAKAMI and Yukio SUZUKI ADE made a kind of hydrophobic blue pigment by phosphatidyl genipin and L-Phenylalanine methyl ester hydrochloride, it showed $\lambda_{\max }$ at $615 \mathrm{~nm}$ in chloroform [8]. It indicates that we got a new water-insoluble gardenia blue pigment.

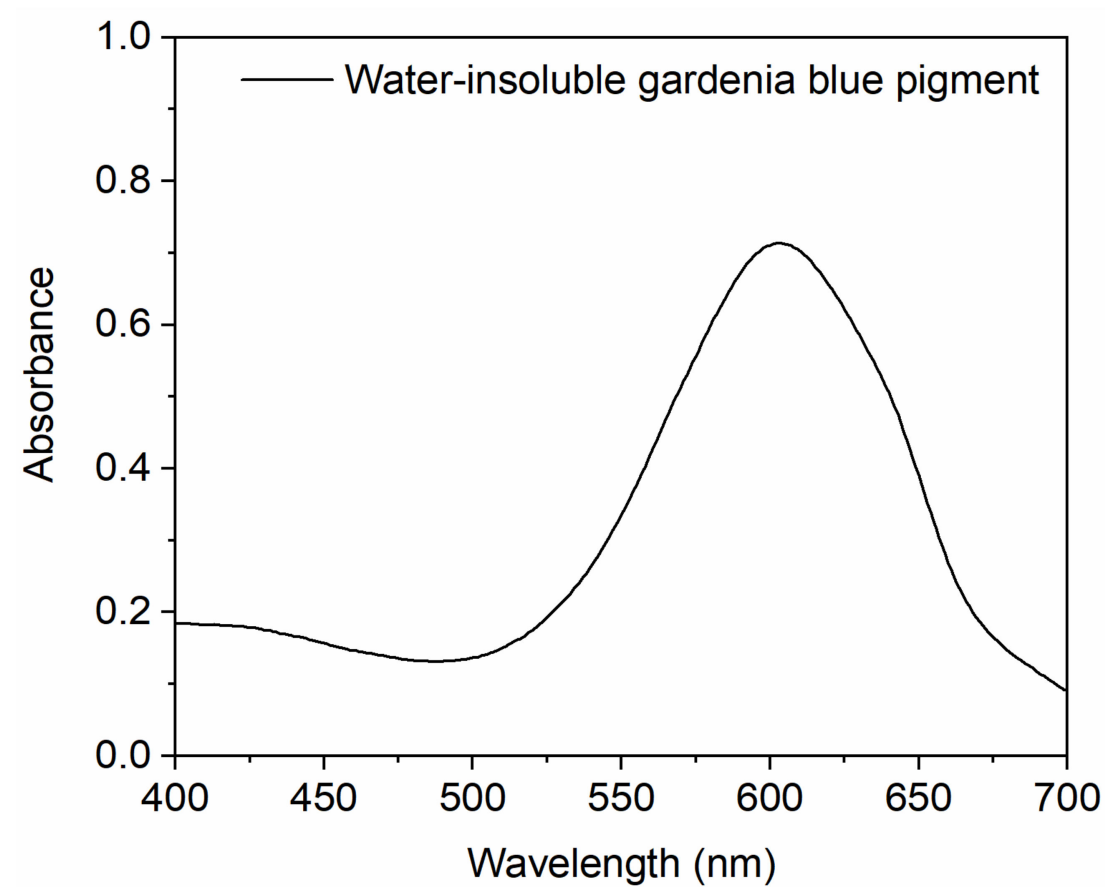

Figure 3. The UV-vis of water-insoluble gardenia blue pigment.

\subsection{The Characteristic Function Group Analysis of Water-Insoluble Gardenia Blue Pigment}

Study on the characteristic functional groups of water-insoluble gardenia blue pigments by FTIR and XPS. The FTIR characteristic peaks were showed in Figure 4: 3264.47 
$(\mathrm{OH}) ; 2952.05(\mathrm{CH}) ; 1738.20(\mathrm{C}=\mathrm{O}) ; 1623.91,1561.40(\mathrm{C}=\mathrm{C}) ; 1283.61,1134.53$ (COOC); 3025.98, 1439.74, 1401.81 (aromatic); 702.38, 743.26 (mono-substituted benzene ring) $\mathrm{cm}^{-1}$. The results showed that the characteristic absorption peaks of $\mathrm{CH}, \mathrm{OCH}_{3}, \mathrm{C}=\mathrm{O}, \mathrm{COOC}$, $\mathrm{C}=\mathrm{C}$, and aromatic can correspond to the FTIR spectra of genipin and L-Phenylalanine methyl ester hydrochloride [2]. The characteristic absorption peaks of $\mathrm{OH}$ became weak due to the lower proportion of the $\mathrm{OH}$ group in the pigment.

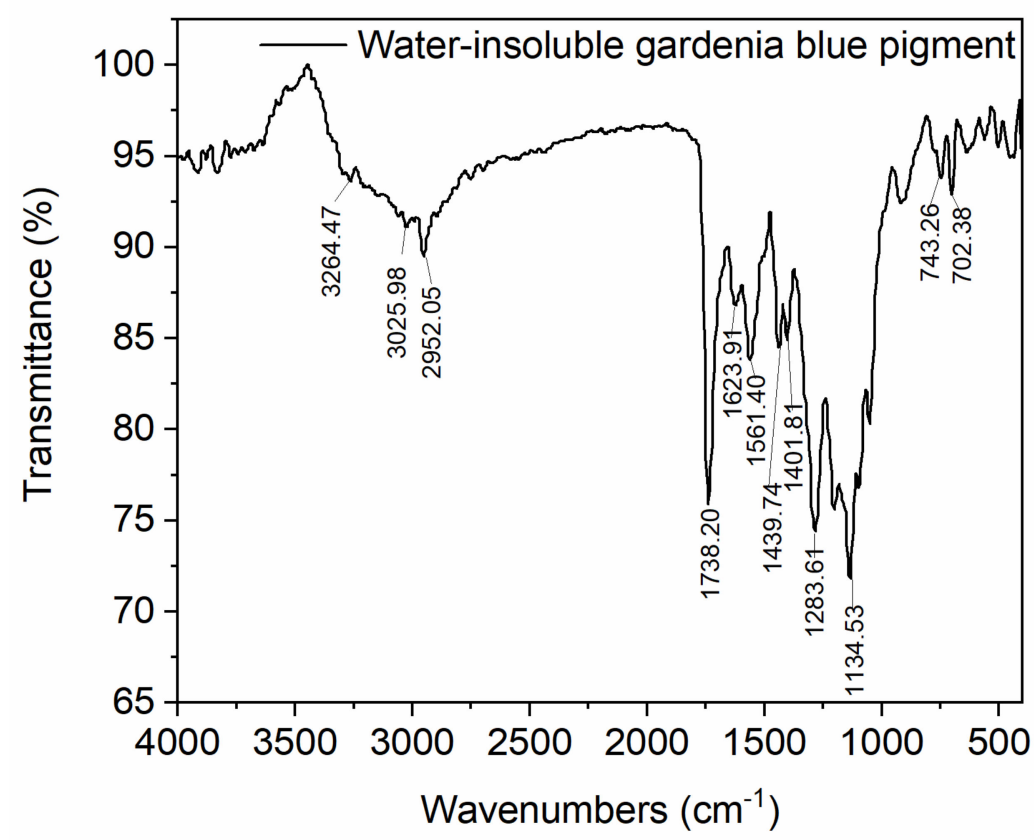

Figure 4. The FTIR of water-insoluble gardenia blue pigment.

The results of the full-spectrum XPS of water-insoluble gardenia blue pigment showed that the major elements of water-insoluble gardenia blue pigment are $\mathrm{C}, \mathrm{N}$, and $\mathrm{O}$, and the content of $\mathrm{C}$ and $\mathrm{O}$ are higher than that of $\mathrm{N}$ (Figure 5a). The method of separating overlapped curves was adopted to analyze C1s, O1s, and N1s peaks (Figure 5b-d). The contents of the functional groups are in Tables $2-4$. The C-1s spectrum of water-insoluble gardenia blue pigment presents main peaks at $284.16 \mathrm{eV}, 284.68 \mathrm{eV}, 286.09 \mathrm{eV}$ related to Sp2 hybrid, C=C, and C-O structures. The O-1s spectrum of water-insoluble gardenia blue pigment presents two peaks at $531.95 \mathrm{eV}$ and $533.47 \mathrm{eV}$ related to $\mathrm{O}-\mathrm{C}$ and $\mathrm{O}=\mathrm{C}$ structures. The N-1s spectrum of water-insoluble gardenia blue pigment presents two peaks at $402.24 \mathrm{eV}$ and $400.57 \mathrm{eV}$ related to C-N-C and C-N structures. As a result, XPS shows that water-insoluble gardenia blue pigment has a $\pi-\pi$ * resonance system, and functional groups are $\mathrm{O}-\mathrm{C}=\mathrm{O}, \mathrm{C}=\mathrm{O}, \mathrm{COOC}, \mathrm{C}-\mathrm{N}, \mathrm{C}=\mathrm{C}$, and benzene ring. 


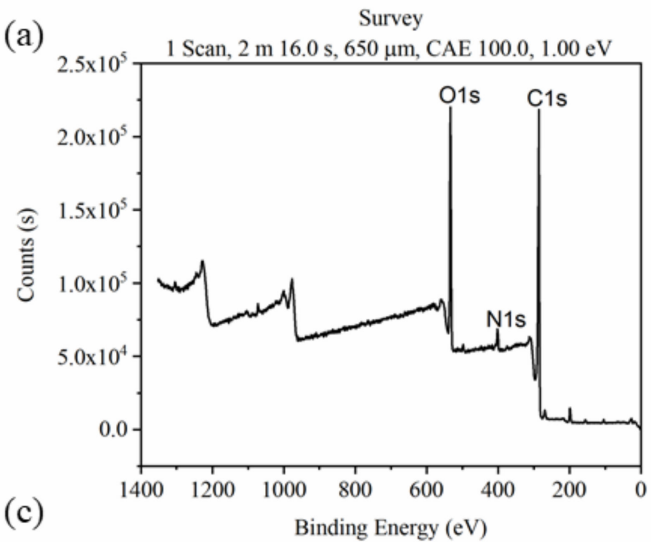

(b)
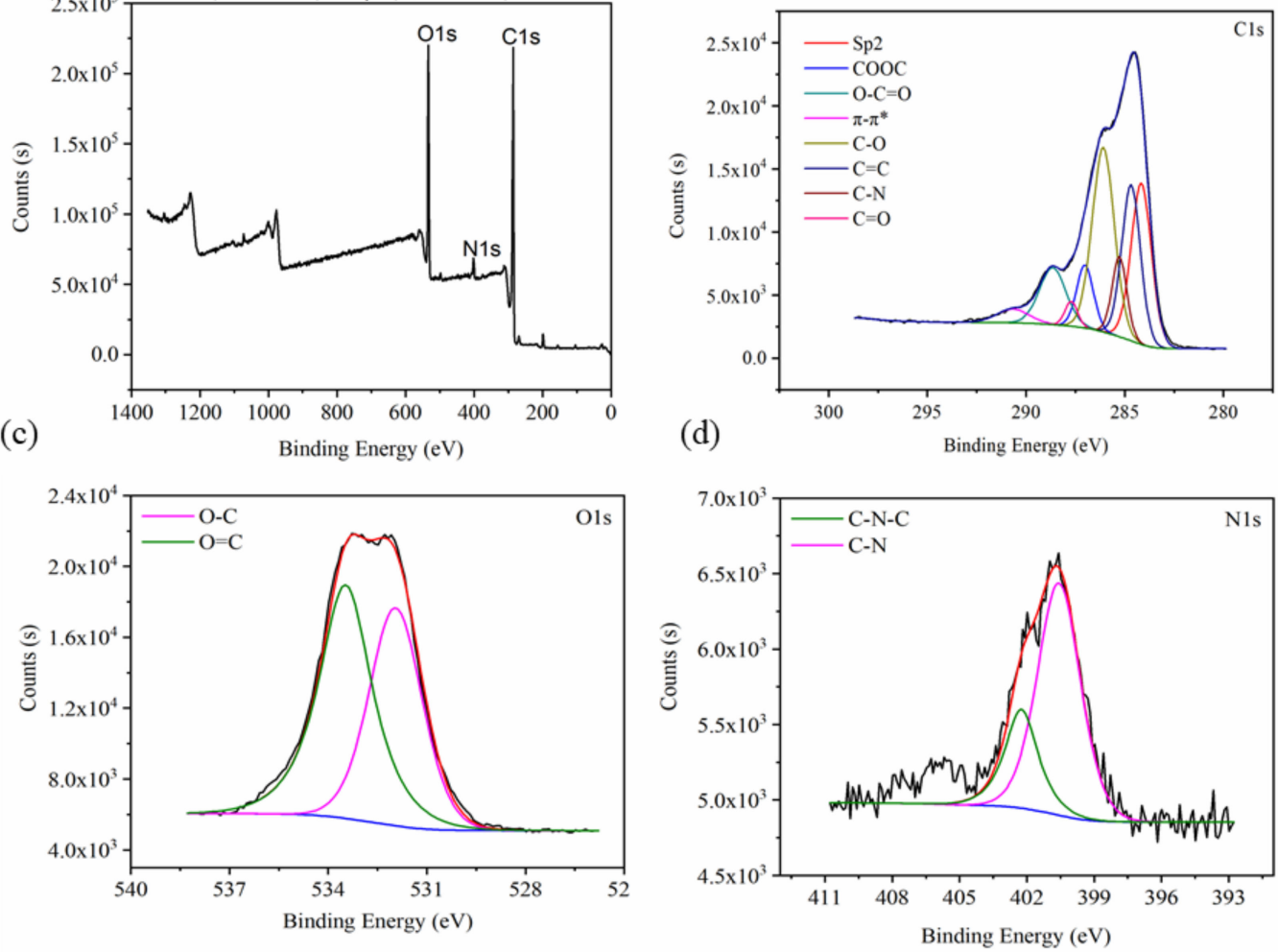

Figure 5. The full-spectrum (a), C1s-spectrum (b), O1s-spectrum (c), and N1s-spectrum (d) XPS of water-insoluble gardenia blue pigment.

Table 2. The surface functional group content of carbon element (C) of water-insoluble gardenia blue pigment.

\begin{tabular}{ccc}
\hline Functional Group & $\mathbf{E}_{\mathbf{b}}(\mathbf{e V})$ & Area $\mathbf{( \% )}$ \\
\hline$\pi-\pi^{*}$ & 290.60 & 3.31 \\
$\mathrm{O}-\mathrm{C}=\mathrm{O}$ & 288.79 & 11.14 \\
$\mathrm{C}=\mathrm{O}$ & 287.78 & 3.02 \\
$\mathrm{COOC}$ & 287.00 & 7.87 \\
$\mathrm{C}-\mathrm{O}$ & 286.09 & 20.83 \\
$\mathrm{C}-\mathrm{N}$ & 285.27 & 9.04 \\
$\mathrm{C}=\mathrm{C}$ & 284.68 & 21.16 \\
$\mathrm{Sp} 2$ & 284.16 & 23.61 \\
\hline
\end{tabular}

Table 3. The surface functional group content of oxygen element $(\mathrm{O})$ of water-insoluble gardenia blue pigment.

\begin{tabular}{ccc}
\hline Functional Group & $\mathbf{E}_{\mathbf{b}}(\mathbf{e V})$ & Area (\%) \\
\hline O-C & 531.95 & 45.7 \\
O=C & 533.47 & 54.3 \\
\hline
\end{tabular}

Table 4. The surface functional group content of nitrogen element $(\mathrm{N})$ of water-insoluble gardenia blue pigment.

\begin{tabular}{ccc}
\hline Functional Group & $\mathbf{E}_{\mathbf{b}}(\mathbf{e V})$ & Area $(\%)$ \\
\hline C-N-C & 402.24 & 26.11 \\
C-N & 400.57 & 73.89 \\
\hline
\end{tabular}




\subsection{TLC Separation of Water-Insoluble Gardenia Blue Pigments}

Six different pigments were obtained after the separation of the water-insoluble gardenia blue pigments by thin-layer chromatography (chloroform ethanol 22:1). The $R_{f}$ values of varying water-insoluble gardenia blue pigment are recorded in Table 5 .

Table 5. The $\mathrm{R}_{\mathrm{f}}$ of different spots of water-insoluble gardenia blue pigment.

\begin{tabular}{cc}
\hline Water-Insoluble Gardenia Blue Pigment & $\mathbf{R}_{\mathbf{f}}$ \\
\hline Z-1 & 0.91 \\
Z-2 & 0.85 \\
Z-3 & 0.63 \\
Z-4 & 0.77 \\
Z-5 & 0.55 \\
Z-6 & 0.42 \\
\hline
\end{tabular}

\subsection{Mass Spectrometry Study of Water-Insoluble Gardenia Blue Pigments}

The positive-ion mode of ESI mass spectra was performed to investigate the structures of water-insoluble gardenia blue pigments, which were coded as follows, Z-1, Z-2, Z-3, Z-4, Z-5, and Z-6.

The first-order mass spectra of the six different water-insoluble gardenia blue pigments $\mathrm{Z}-1-\mathrm{Z}-6$ showed the molecular weights of the pigments. The $[\mathrm{M}+\mathrm{Na}]^{+}$ion was selected as the precursor ion in the MS/MS experiment to give fragmentation information. Table 6 shows the mass and composition of the $\mathrm{Na}^{+}$adduct ions $[\mathrm{M}+\mathrm{Na}]^{+}$and main compound ions of the pigments.

Table 6. Accurate mass measurements and elemental compositions of the $\mathrm{Na}^{+}$adduct ions and main product ions by $\mathrm{Q}-\mathrm{TOF}$ MS/MS analysis of the six different water-insoluble gardenia blue pigments Z-1-Z-6.

\begin{tabular}{|c|c|c|c|c|}
\hline Pigments & {$[\mathbf{M}+\mathrm{Na}]^{+}$Ion $(m / z)$} & $\begin{array}{c}\text { Molecular Weight } \\
\text { (Da) }\end{array}$ & $\begin{array}{l}\text { Major Fragment of [M } \\
+\mathrm{Na}]^{+}(m / z)\end{array}$ & Chemical Formula \\
\hline \multirow{3}{*}{$\mathrm{Z}-1$} & \multirow{3}{*}{713.1054} & \multirow{3}{*}{690.1156} & 550.0521 & \multirow{3}{*}{$\mathrm{C}_{41} \mathrm{H}_{42} \mathrm{~N}_{2} \mathrm{O}_{8}$} \\
\hline & & & 387.0005 & \\
\hline & & & 120.9893 & \\
\hline \multirow{4}{*}{$\mathrm{Z}-2$} & \multirow{5}{*}{743.1124} & \multirow{4}{*}{720.1226} & 580.0592 & \multirow{4}{*}{$\mathrm{C}_{42} \mathrm{H}_{44} \mathrm{~N}_{2} \mathrm{O}_{9}$} \\
\hline & & & 549.0453 & \\
\hline & & & 387.0007 & \\
\hline & & & 120.9893 & \\
\hline \multirow{4}{*}{ Z-3 } & & \multirow{4}{*}{708.1246} & 568.0598 & \multirow{4}{*}{$\mathrm{C}_{41} \mathrm{H}_{44} \mathrm{~N}_{2} \mathrm{O}_{9}$} \\
\hline & \multirow{3}{*}{731.1144} & & 553.0389 & \\
\hline & & & 380.0172 & \\
\hline & & & 120.9898 & \\
\hline \multirow{3}{*}{$\mathrm{Z}-4$} & \multirow{3}{*}{699.2772} & \multirow{3}{*}{676.2874} & 536.0379 & \multirow{3}{*}{ / } \\
\hline & & & 373.9934 & \\
\hline & & & 120.9894 & \\
\hline \multirow{8}{*}{ Z-5 } & \multirow{8}{*}{1068.437} & \multirow{8}{*}{1045.447} & 1036.185 & \multirow{8}{*}{ / } \\
\hline & & & 1006.177 & \\
\hline & & & 847.1269 & \\
\hline & & & 739.0832 & \\
\hline & & & 605.0628 & \\
\hline & & & 549.0437 & \\
\hline & & & 364.0243 & \\
\hline & & & 120.9891 & \\
\hline \multirow{4}{*}{ Z-6 } & \multirow{4}{*}{705.0953} & \multirow{4}{*}{682.1055} & 616.555 & \multirow{4}{*}{ / } \\
\hline & & & 542.038 & \\
\hline & & & 364.025 & \\
\hline & & & 120.9898 & \\
\hline
\end{tabular}


In the first-order MS of water-insoluble gardenia blue pigment $\mathrm{Z}-1$, the $[\mathrm{M}+\mathrm{Na}]^{+}$ion at $m / z 713.1054$ was studied as the base peak, which proved that the formula weight of the water-insoluble gardenia blue pigment Z-1 is $690.1156 \mathrm{Da}$ (the formula weight of sodium (Na) is $22.9898 \mathrm{Da})$. The precursor ion $\left(\left[\mathrm{M}+\mathrm{Na}^{+}\right)\right.$in the MS/MS test could offer varying fragmentation information. The product ion $(\mathrm{m} / \mathrm{z} 550.0521)$ had the highest abundance and the product $(\mathrm{m} / \mathrm{z}$ 387.0005) corresponded to the loss of two $\Delta \mathrm{m}=163$ fragments of L-Phenylalanine methyl ester hydrochloride. More peaks simultaneously appeared at $\mathrm{m} / \mathrm{z} 120.9893$ because of ring cleavage, which corresponded to the loss of a $\Delta \mathrm{m}=266$ fragment. The fragmentation pattern of waterinsoluble gardenia blue pigment Z-1 is shown in Figure 6a. The structure of water-insoluble gardenia blue pigment Z-1 had significantly better functional substituents and the cleavage of the basic skeleton of the product. Then we can also deduce that the chemical formula of waterinsoluble gardenia blue pigment $\mathrm{Z}-1$ is $\mathrm{C}_{41} \mathrm{H}_{42} \mathrm{~N}_{2} \mathrm{O}_{8}$. The planar and 3D molecular structure simulation graphs are shown in Figure $6 b, c$.

(a)
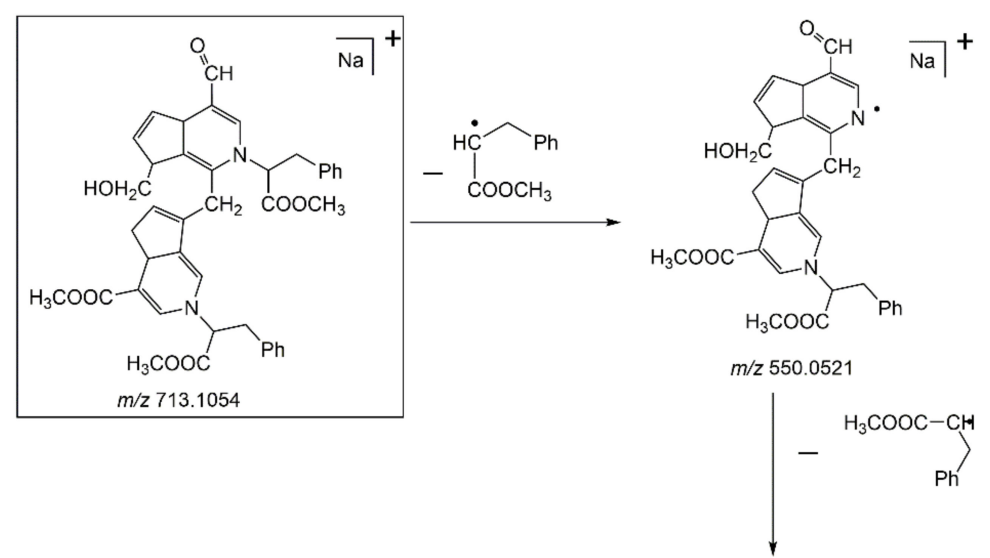

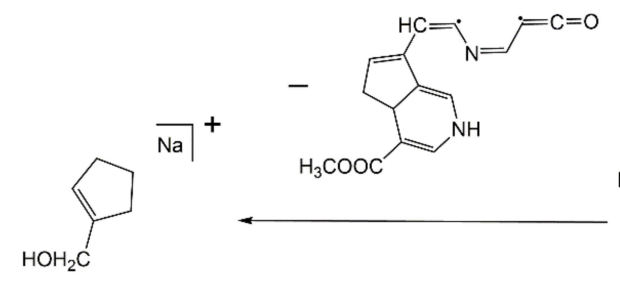

$m / z 120.9893$

(b)

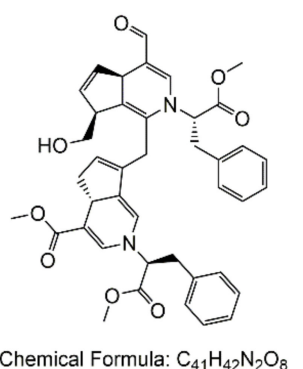

(c)

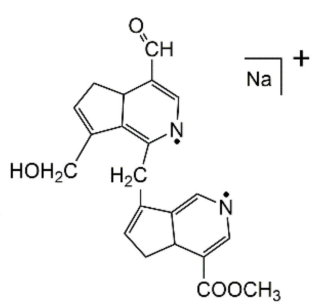

$\mathrm{m} / \mathrm{z} 387.0005$

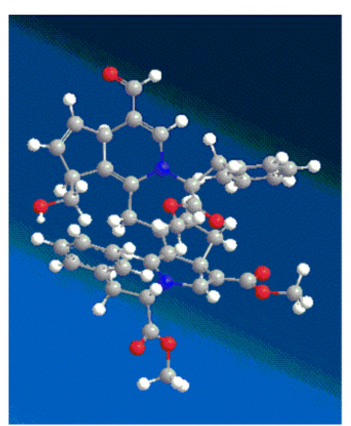

Figure 6. The fragmentation pathway of water-insoluble gardenia blue pigment Z-1 (a). The planar and 3D molecular structure simulation graphs of the pigment Z-1 (b) and (c) (C-gray, O-red, N-blue, H-white).

In the first-order MS of water-insoluble gardenia blue pigment $\mathrm{Z}-2$, the $[\mathrm{M}+\mathrm{Na}]^{+}$ ion at $m / z 743.1124$ was researched as the base peak, which proves the formula weight of the water-insoluble gardenia blue pigment Z-2 is $720.1226 \mathrm{Da}$. The precursor ion ([M 
$+\mathrm{Na}]^{+}$) in the MS/MS test could offer more fragmentation information. The product ion is at $\mathrm{m} / \mathrm{z} 580.0592$ with low abundance, and it corresponded to the loss of a $\Delta \mathrm{m}$ $=163$ fragment of L-Phenylalanine methyl ester hydrochloride. It is similar to waterinsoluble gardenia blue pigment $\mathrm{Z}-1$. With the loss of $-\mathrm{OCH}_{3}(\Delta \mathrm{m}=31)$, further peaks simultaneously appeared at $m / z 549.0453$, which was the highest abundance. The fragment ion at $m / z 387.0007$ was produced by the loss of a $\Delta \mathrm{m}=162$ fragment of L-Phenylalanine methyl ester hydrochloride. As water-insoluble gardenia blue pigment Z-1, further peaks simultaneously appeared at $\mathrm{m} / \mathrm{z} 120.9893$ because of ring cleavage, and it corresponded to the loss of a $\Delta \mathrm{m}=266$ fragment. The fragmentation pattern of water-insoluble gardenia blue pigment Z-2 is shown in Figure 7a. The structure of water-insoluble gardenia blue pigment Z-2 can be deduced by the functional substituents and the cleavage of the basic skeleton of the product. In this way, we can deduce that the chemical formula of waterinsoluble gardenia blue pigment $\mathrm{Z}-2$ is $\mathrm{C}_{42} \mathrm{H}_{44} \mathrm{~N}_{2} \mathrm{O}_{9}$. The planar and $3 \mathrm{D}$ molecular structure simulation graphs are shown in Figure $7 \mathrm{~b}, \mathrm{c}$.

(a)

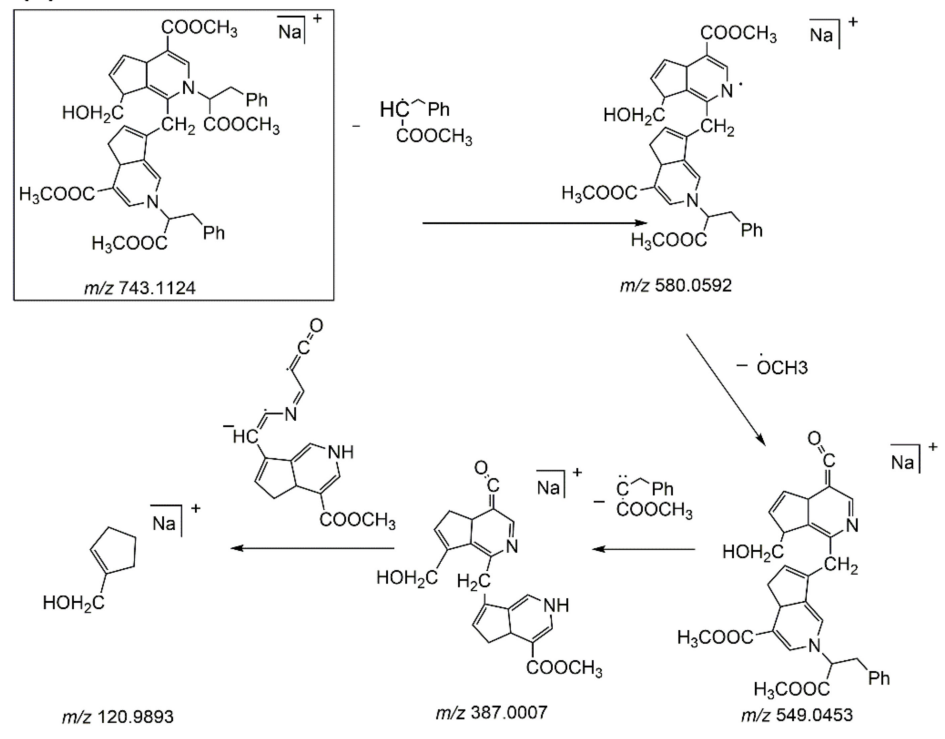

(b)

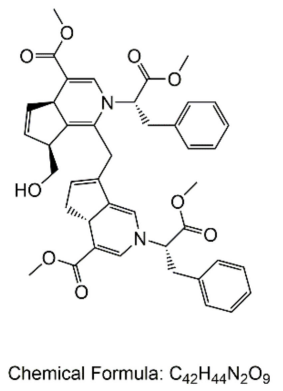

(c)

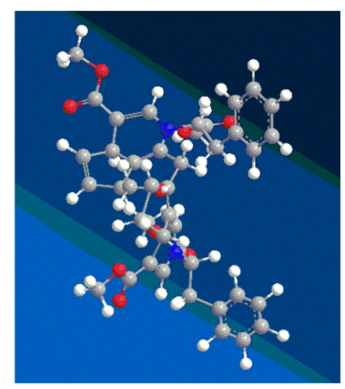

Figure 7. The fragmentation pathway of water-insoluble gardenia blue pigment $Z-2$ (a). The planar and 3D molecular structure simulation graphs of the pigment Z-2 (b) and (c) (C-ray, O-red, N-blue, H-white).

In the first-order MS of water-insoluble gardenia blue pigment $\mathrm{Z}-3$, the $[\mathrm{M}+\mathrm{Na}]^{+}$ ion at $m / z 731.1144$ was tested as the base peak which proves the formula weight of the water-insoluble gardenia blue pigment Z-3 is $708.1246 \mathrm{Da}$. The precursor ion $\left([\mathrm{M}+\mathrm{Na}]^{+}\right)$ in the MS/MS test could offer more fragmentation information. The product ion is at $\mathrm{m} / \mathrm{z} 568.0598$ with the highest abundance, and it corresponded to the loss of a $\Delta \mathrm{m}=163$ fragment of L-Phenylalanine methyl ester hydrochloride, it is similar to water-insoluble 
gardenia blue pigments Z-1 and Z-2. With the loss of $-\mathrm{CH}_{3}(\Delta \mathrm{m}=15)$, further peaks simultaneously appeared at $m / z$ 553.0389. The fragment ion at $m / z 380.0172$ was produced by the loss of a $\Delta \mathrm{m}=173$ fragment. Different from water-insoluble gardenia blue pigments Z-1 and Z-2, further peak simultaneously appeared at $m / z 120.9898$ because of ring cleavage, and it corresponded to the loss of a $\Delta \mathrm{m}=259$ fragment. The fragmentation pattern of water-insoluble gardenia blue pigment Z-3 is shown in Figure 8a. The structure of waterinsoluble gardenia blue pigment Z-3 can be deduced by the functional substituents and the cleavage of the basic skeleton of the product. In this way, we can deduce that the chemical formula of water-insoluble gardenia blue pigment Z-3 is $\mathrm{C}_{41} \mathrm{H}_{44} \mathrm{~N}_{2} \mathrm{O}_{9}$. The planar and 3D molecular structure simulation graphs are shown in Figure 8b,c.

(a)
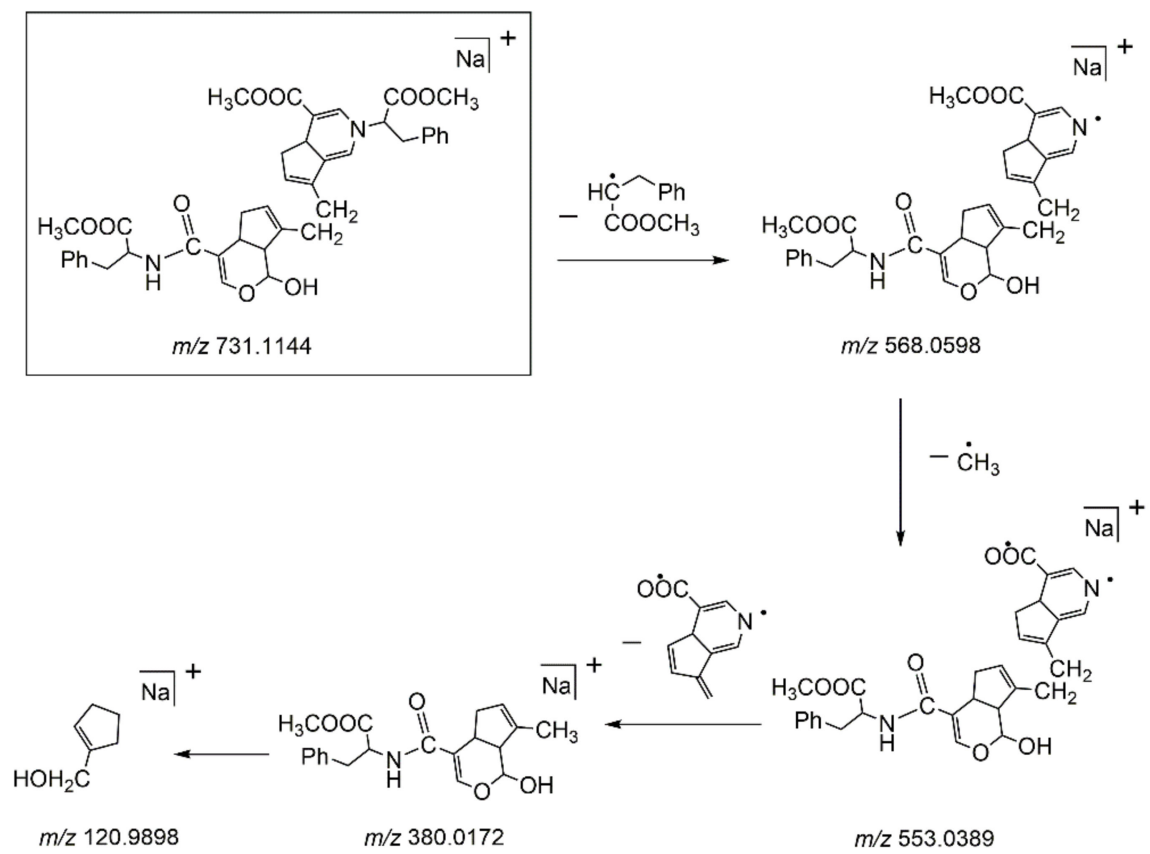

(b)

(c)
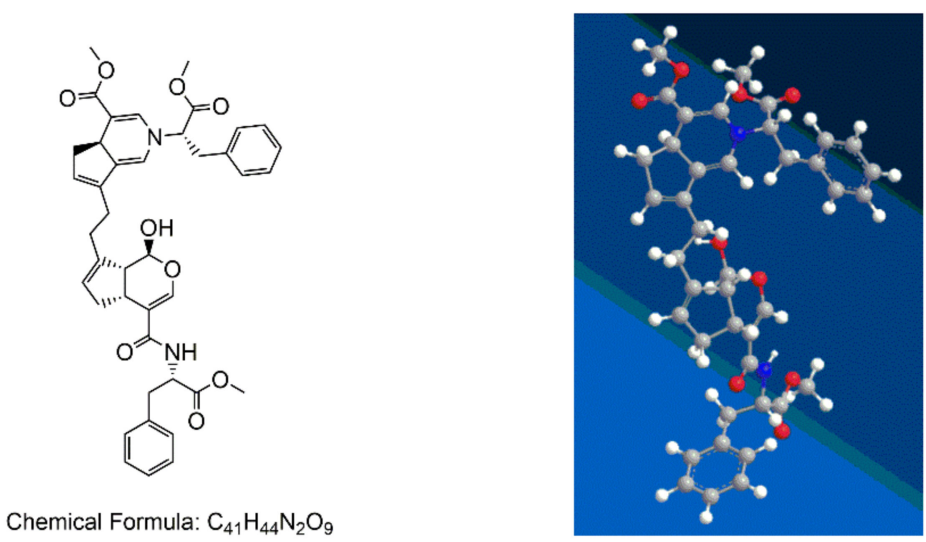

Figure 8. The fragmentation pathway of water-insoluble gardenia blue pigment Z-3 (a). The planar and 3D molecular structure simulation graphs of the pigment Z-3 (b) and (c) (C-gray, O-red, N-blue, H-white).

In the first-order MS of water-insoluble gardenia blue pigments Z-4-Z-6, the $[\mathrm{M}+\mathrm{Na}]^{+}$ ions at $m / z$ 699.2772, 1068.4367, and 705.0953, were observed as the base peaks which prove that the formula weights of them are $676.2874,1045.4469$, and $682.1055 \mathrm{Da}$. The $[\mathrm{M}+\mathrm{Na}]^{+}$ 
ions were voted as the precursor ion in the MS/MS test that could give more fragmentation information. The fragment ions of water-insoluble gardenia blue pigments Z-4-Z-6 were at $m / z 536.0379,373.9934,120.9894, \mathrm{~m} / \mathrm{z} 1036.1850,1006.1770,847.1269,739.0832,605.0628$, $549.0437,364.0243,120.9891$, and $m / z 616.5550,542.0380,364.0250,120.9898$ respectively. Since the decomposition processes of water-insoluble gardenia blue pigments Z-4-Z-6 are different from the water-insoluble gardenia blue pigments Z-1-Z-3, and there are no published papers saying much, the structures, fragmentation pattern, and chemical formulas of water-insoluble gardenia blue pigments Z-4-Z-6 have not been deduced yet.

\subsection{Solubility Study of Gardenia Blue Pigment}

The results of the solubility of water-soluble and water-insoluble gardenia blue pigments in different solvents are shown in Table 7. It is concluded that the water-insoluble gardenia blue pigment is not soluble in water. Whereas the water-insoluble gardenia blue pigment can be dissolved in highly polar organic solvents, for example, acetonitrile, methanol, ethanol, acetone, ethyl acetate, and chloroform, it is not dissolved in weak polar organic solvents, for instance, ethyl ether, and petroleum ether.

Table 7. Solubility of water-soluble and water-insoluble gardenia blue pigments.

\begin{tabular}{ccc}
\hline Pigments & Water-Soluble & Water-Insoluble \\
\hline Water & $\sqrt{ }$ & $\times$ \\
Dimethyl sulfoxide (DMSO) & $\sqrt{ }$ & $\sqrt{ }$ \\
Acetonitrile & $\times$ & $\sqrt{ }$ \\
Methanol & $\times$ & $\sqrt{ }$ \\
Ethanol & $\times$ & $\sqrt{ }$ \\
Acetone & $\times$ & $\sqrt{ }$ \\
Ethyl acetate & $\times$ & $\sqrt{ }$ \\
Chloroform & $\times$ & $\times$ \\
Ethyl ether & $\times$ & $\times$ \\
Petroleum ether & $\times$ &
\end{tabular}

Note. $\sqrt{ }$, easily soluble; $\times$, insoluble.

\subsection{Stability Study of Gardenia Blue Pigment}

To investigate the light stability of water-soluble and water-insoluble gardenia blue pigments, the experiments were carried out under four different light conditions: sunlight (40,000 lux), lamplight (13,000 lux), room light (300 lux), and dark (control) for 7 days. The residual rate of the pigments is shown in Figure 9.

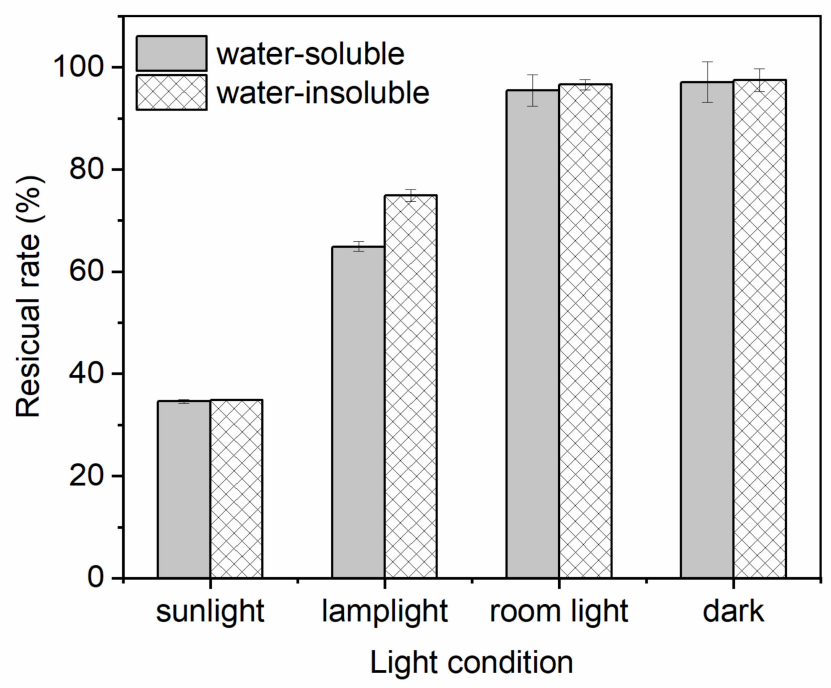

Figure 9. Light stability of water-soluble and water-insoluble gardenia blue pigments (residual rate). 
It was found that the stability of water-insoluble gardenia blue pigment under lamplight was significantly better than that water-soluble gardenia blue pigment $(p<0.05)$, and the residual rate of it was $74.9 \%$. However, there were no obvious differences between the water-soluble gardenia blue pigment and water-insoluble gardenia blue pigment under the light conditions: sunlight, room light, and dark $(p>0.05)$. Furthermore, the results of color properties (Table 8) were consistent with the residual rate. Under the lamplight condition, there was an apparent difference of the $\Delta L^{*}, \Delta a^{*}, \Delta b^{*}, \Delta C_{a b}^{*}$, and $\Delta E_{L a b}^{*}$ between the two pigments $(p<0.05)$, the stability of water-insoluble gardenia blue pigment was significantly better than water-soluble gardenia blue pigment. However, there were no obvious differences of $\Delta L^{*}$, and $\Delta E_{L a b}^{*}$ between the water-soluble gardenia blue pigment and water-insoluble gardenia blue pigment under the light conditions: sunlight, room light, and dark $(p>0.05)$.

Table 8. Light stability of water-soluble and water-insoluble gardenia blue pigments (color properties).

\begin{tabular}{|c|c|c|c|c|c|c|}
\hline $\begin{array}{c}\text { Light } \\
\text { Condition }\end{array}$ & Pigment & $\Delta L^{*}$ & $\Delta a^{*}$ & $\begin{array}{c}\text { Color Properties } \\
\qquad \Delta b^{*}\end{array}$ & $\Delta C_{a b}^{*}$ & $\Delta E_{L a b}^{*}$ \\
\hline \multirow{2}{*}{$\begin{array}{c}\text { Sunlight }(40,000 \\
\text { lux })\end{array}$} & Water-soluble & $24.41 \pm 0.66^{\mathrm{a}}$ & $10.80 \pm 0.19^{b}$ & $24.16 \pm 0.22^{a}$ & $-26.46 \pm 0.28^{a}$ & $36.00 \pm 0.24^{a}$ \\
\hline & Water-insoluble & $24.80 \pm 0.54^{\mathrm{a}}$ & $24.61 \pm 0.43^{\mathrm{a}}$ & $15.08 \pm 0.68^{b}$ & $-27.76 \pm 0.80^{a}$ & $38.05 \pm 0.91^{\mathrm{a}}$ \\
\hline \multirow{2}{*}{$\begin{array}{l}\text { Lamplight } \\
(13,000 \text { lux })\end{array}$} & Water-soluble & $9.80 \pm 0.30^{\mathrm{a}}$ & $6.82 \pm 0.16^{\mathrm{a}}$ & $11.44 \pm 0.50^{\mathrm{a}}$ & $-13.18 \pm 0.53^{b}$ & $16.54 \pm 0.59^{a}$ \\
\hline & Water-insoluble & $6.84 \pm 0.01^{b}$ & $3.78 \pm 0.08^{b}$ & $2.30 \pm 0.13^{b}$ & $-4.34 \pm 0.14^{\mathrm{a}}$ & $8.15 \pm 0.06^{b}$ \\
\hline \multirow{2}{*}{$\begin{array}{l}\text { Room light (300 } \\
\text { lux) }\end{array}$} & Water-soluble & $0.66 \pm 0.01^{\mathrm{a}}$ & $2.31 \pm 0.18^{a}$ & $0.96 \pm 0.01^{\mathrm{a}}$ & $-1.78 \pm 0.06^{b}$ & $2.59 \pm 0.15^{\mathrm{a}}$ \\
\hline & Water-insoluble & $-0.39 \pm 0.13^{a}$ & $0.89 \pm 0.04^{b}$ & $-0.96 \pm 0.01^{b}$ & $-0.01 \pm 0.03^{\mathrm{a}}$ & $1.36 \pm 0.06^{\mathrm{a}}$ \\
\hline \multirow{2}{*}{ Dark (control) } & Water-soluble & $0.32 \pm 0.13^{\mathrm{a}}$ & $1.73 \pm 0.19^{a}$ & $0.53 \pm 0.07^{\mathrm{a}}$ & $-1.28 \pm 0.14^{\mathrm{b}}$ & $1.80 \pm 0.21^{\mathrm{a}}$ \\
\hline & Water-insoluble & $-0.85 \pm 0.11^{\mathrm{a}}$ & $0.87 \pm 0.03^{b}$ & $-1.00 \pm 0.01^{b}$ & $0.03 \pm 0.03^{a}$ & $1.58 \pm 0.06^{\mathrm{a}}$ \\
\hline
\end{tabular}

Note. The same letter means there is no obvious difference $(p>0.05)$; The different letters mean there is a significant difference $(p<0.05)$.

In previous studies, Zhang (2008a) studied the light stability of the hydrophobic gardenia blue pigment, which was made from the esterification of acetic anhydride and water-soluble gardenia blue pigment. The result showed that the residual rate of the pigment was $52.8 \%$ under 12,000 lux for 28 days.

To investigate the temperature stability of water-soluble and water-insoluble gardenia blue pigments, the experiments were carried out under different heat conditions: $4{ }^{\circ} \mathrm{C}, 40^{\circ} \mathrm{C}, 60^{\circ} \mathrm{C}$, $80^{\circ} \mathrm{C}, 100^{\circ} \mathrm{C}$, and $120^{\circ} \mathrm{C}$, and room temperature (control) for $24 \mathrm{~h}$. The residual rates of the pigments are shown in Figure 10.

It was found that the stability of water-insoluble gardenia blue pigment under $80-120^{\circ} \mathrm{C}$ was significantly better than that water-soluble gardenia blue pigment $(p<0.05)$, and the residual rates of it were $95.26,88.27$, and $87.72 \%$ respectively. However, there were no obvious differences between the water-soluble gardenia blue pigment and waterinsoluble gardenia blue pigment under $4-60{ }^{\circ} \mathrm{C}(p>0.05)$. Furthermore, the results of color properties (Table 9) were consistent with the residual rate. Under $60-120^{\circ} \mathrm{C}$ as there was an apparent difference regarding the $\Delta L^{*}, \Delta a^{*}, \Delta b^{*}, \Delta C_{a b}^{*}$, and $\Delta E_{L a b}^{*}$ between the two pigments $(p<0.05)$, and the stability of water-insoluble gardenia blue pigment was significantly better than water-soluble gardenia blue pigment 


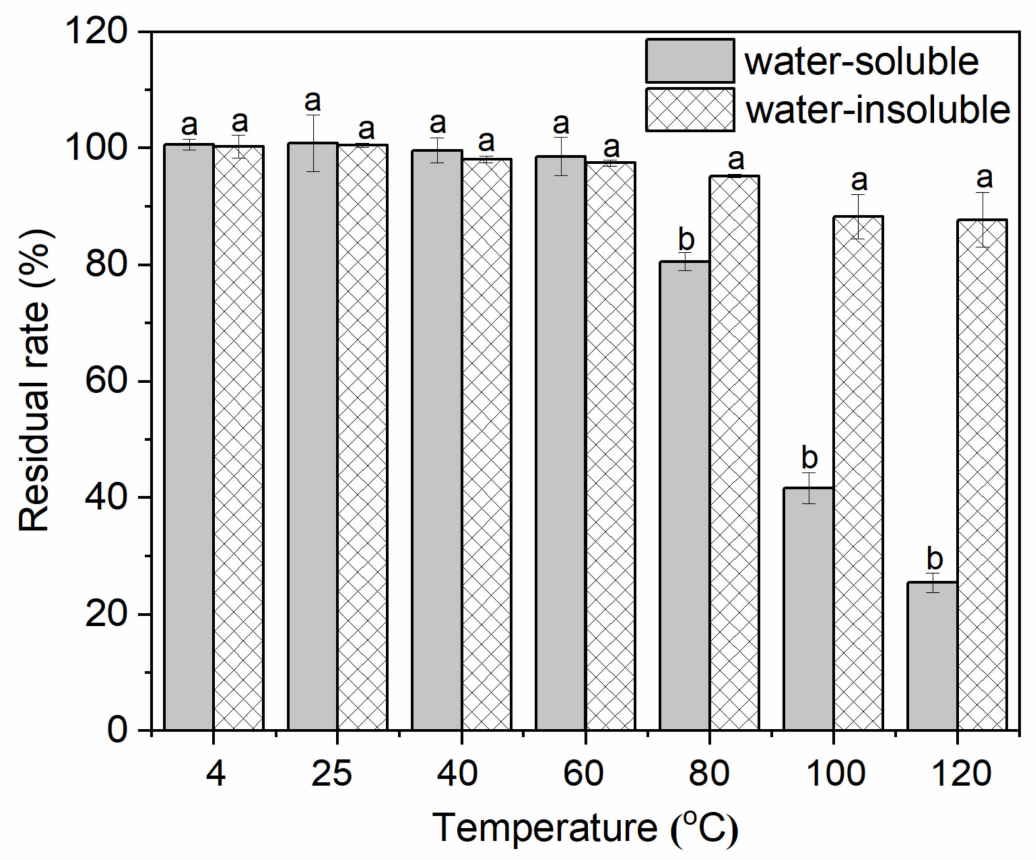

Figure 10. Temperature stability of water-soluble and water-insoluble gardenia blue pigments (residual rate). Different latters mean there is a significant difference $(p<0.05)$.

Table 9. Temperature stability of water-soluble and water-insoluble gardenia blue pigments (color properties).

\begin{tabular}{|c|c|c|c|c|c|c|}
\hline $\begin{array}{l}\text { Temperature } \\
\text { Condition }\end{array}$ & Pigment & $\Delta L^{*}$ & $\Delta a^{*}$ & $\begin{array}{l}\text { Color Properties } \\
\qquad \Delta b^{*}\end{array}$ & $\Delta C_{a b}^{*}$ & $\Delta E_{L a b}^{*}$ \\
\hline \multirow{2}{*}{$4^{\circ} \mathrm{C}$} & water-soluble & $0.24 \pm 0.06^{\mathrm{a}}$ & $-0.51 \pm 0.04^{\mathrm{a}}$ & $-0.20 \pm 0.01^{a}$ & $0.08 \pm 0.44^{\mathrm{a}}$ & $0.60 \pm 0.06^{\mathrm{a}}$ \\
\hline & water-insoluble & $-1.00 \pm 1.39^{a}$ & $0.91 \pm 1.08^{\mathrm{a}}$ & $0.96 \pm 1.17^{\mathrm{a}}$ & $-1.45 \pm 1.79^{\mathrm{a}}$ & $1.67 \pm 2.09^{a}$ \\
\hline \multirow{2}{*}{$25^{\circ} \mathrm{C}$ (control) } & water-soluble & $1.41 \pm 0.02^{\mathrm{a}}$ & $0.11 \pm 0.03^{\mathrm{a}}$ & $0.74 \pm 0.09^{a}$ & $-1.27 \pm 0.70^{\mathrm{a}}$ & $1.59 \pm 0.06^{\mathrm{a}}$ \\
\hline & water-insoluble & $0.14 \pm 0.01^{b}$ & $0.25 \pm 0.06^{\mathrm{a}}$ & $-0.06 \pm 0.07^{\mathrm{b}}$ & $-0.08 \pm 0.18^{a}$ & $0.44 \pm 0.16^{b}$ \\
\hline \multirow[b]{2}{*}{$40^{\circ} \mathrm{C}$} & water-soluble & $0.40 \pm 0.03^{a}$ & $1.30 \pm 0.01^{\mathrm{a}}$ & $0.79 \pm 0.05^{\mathrm{a}}$ & $-1.86 \pm 0.86^{\mathrm{a}}$ & $1.57 \pm 0.04^{\mathrm{a}}$ \\
\hline & water-insoluble & $-1.22 \pm 1.10^{a}$ & $1.22 \pm 0.79^{\mathrm{a}}$ & $-0.98 \pm 1.27^{\mathrm{a}}$ & $-1.84 \pm 1.98^{a}$ & $2.03 \pm 1.74^{\mathrm{a}}$ \\
\hline \multirow{2}{*}{$60^{\circ} \mathrm{C}$} & water-soluble & $0.75 \pm 0.11^{\mathrm{a}}$ & $3.21 \pm 0.16^{\mathrm{a}}$ & $2.36 \pm 0.36^{\mathrm{a}}$ & $-3.68 \pm 0.15^{b}$ & $4.06 \pm 0.11^{\mathrm{a}}$ \\
\hline & water-insoluble & $0.07 \pm 0.06^{\mathrm{a}}$ & $1.32 \pm 0.47^{b}$ & $0.51 \pm 0.11^{b}$ & $-0.81 \pm 1.14^{\mathrm{a}}$ & $1.32 \pm 0.62^{b}$ \\
\hline \multirow{2}{*}{$80{ }^{\circ} \mathrm{C}$} & water-soluble & $7.66 \pm 0.46^{\mathrm{a}}$ & $1.55 \pm 0.59^{\mathrm{a}}$ & $4.38 \pm 0.85^{\mathrm{a}}$ & $-5.00 \pm 0.01^{\mathrm{a}}$ & $8.99 \pm 0.08^{a}$ \\
\hline & water-insoluble & $-1.05 \pm 0.05^{b}$ & $3.21 \pm 0.33^{\mathrm{a}}$ & $1.45 \pm 0.21^{\mathrm{b}}$ & $-4.67 \pm 1.48^{a}$ & $3.67 \pm 0.38^{b}$ \\
\hline \multirow{2}{*}{$100^{\circ} \mathrm{C}$} & water-soluble & $18.04 \pm 1.34^{\mathrm{a}}$ & $17.20 \pm 0.30^{\mathrm{a}}$ & $26.78 \pm 0.31^{\mathrm{a}}$ & $-29.27 \pm 0.60^{b}$ & $36.59 \pm 1.03^{a}$ \\
\hline & water-insoluble & $-2.70 \pm 0.45^{b}$ & $9.80 \pm 0.57^{b}$ & $6.05 \pm 0.50^{b}$ & $-10.61 \pm 1.72^{\mathrm{a}}$ & $13.07 \pm 1.12^{b}$ \\
\hline \multirow{2}{*}{$120^{\circ} \mathrm{C}$} & water-soluble & $26.61 \pm 1.58^{\mathrm{a}}$ & $19.43 \pm 0.95^{\mathrm{a}}$ & $35.45 \pm 1.24^{\mathrm{a}}$ & $-32.69 \pm 0.10^{b}$ & $48.39 \pm 2.15^{\mathrm{a}}$ \\
\hline & water-insoluble & $-4.51 \pm 1.26^{b}$ & $11.67 \pm 1.08^{b}$ & $8.95 \pm 0.50^{b}$ & $-13.90 \pm 1.47^{\mathrm{a}}$ & $15.43 \pm 0.16^{b}$ \\
\hline
\end{tabular}

Note. The same letter means there is no obvious difference $(p>0.05)$; The different letters mean there is a significant difference $(p<0.05)$.

\section{Conclusions}

Based on molecular simulations, the synthetic route of water-insoluble gardenia blue pigment was prepared by the reaction of genipin and L-Phenylalanine methyl ester hydrochloride. After extraction and purification, we got a highly purified water-insoluble gardenia blue pigment with a high color value of 288. The result of SEM showed that the surface of the pigment was largely smooth and spherical. The UV absorbance wavelength showed that the $\lambda_{\max }$ of the pigment was $607 \mathrm{~nm}$ in ethanol, and the main functional groups include $\mathrm{O}-\mathrm{C}=\mathrm{O}, \mathrm{C}=\mathrm{O}, \mathrm{C}-\mathrm{N}, \mathrm{C}=\mathrm{C}, \mathrm{OH}$, and benzene ring. The results presented six different molecular weights and chemical structures of pigments, and the particular structures and formation mechanisms of three kinds of pigments were speculated (their molecular weights are $690.1156 \mathrm{Da}, 720.1226 \mathrm{Da}$, and $708.1246 \mathrm{Da}$, respectively). The pigment was only able to be dissolved in ethanol, methanol, acetone, ethyl acetate, and other strong polar organic 
solvents, but was unable to be dissolved in water, ethyl ether, petroleum ether, or other weak polar organic solvents. In terms of light and thermal stabilities, water-insoluble gardenia blue pigment is significantly better than water-soluble gardenia blue pigment $(p<0.05)$. When it is under direct light for 7 days or incubated at $80-120^{\circ} \mathrm{C}$ for $24 \mathrm{~h}$, the pigment residual rates were $74.90,95.26,88.27$, and $87.72 \%$, respectively.

Author Contributions: G.L. conceptualized the idea, revised, make corrections and approved the research article for publication, Y.G., R.N. and J.D. performed the experiments, Y.G., J.X., D.X. and C.W. analyzed the results, Y.G., and J.X. wrote the first draft of the manuscript. All authors have read and agreed to the published version of the manuscript.

Funding: This project was funded by the National Key R\&D Program of China (2019YFC1606200), the Natural Science Foundation of China (No. 31871772; No. 31671832), the Beijing Natural Science Foundation (Grant No. 6192003), School Level Cultivation Fund of Beijing Technology and Business University for Distinguished and Excellent Young Scholars (BTBUYP2022), 2021 Postgraduate Scientific Research Ability Improvement Project of Beijing business and Technology University and Graduate Innovation Project of School of Food and Health in 2021.

Institutional Review Board Statement: Not applicable.

Informed Consent Statement: Not applicable.

Data Availability Statement: The datasets used and/or analyzed during the current study are available from the correspond-ing author on reasonable request.

Conflicts of Interest: There is no conflict of interests regarding the publication of this paper.

\section{References}

1. Jespersen, L.; Stromdahl, L.D.; Olsen, K.; Skibsted, L.H. Heat and light stability of three natural blue colorants for use in confectionery and beverages. Eur. Food Res. Technol. 2005, 220, 261-266. [CrossRef]

2. Wu, S.; Wu, Q.; Xu, L.; Xu, L.J. Progress in the development and application of natural edible pigment. Shandong Food Ferment. 2015, 179, 35-38.

3. Li, Z.; Hu, C.; Jia, J.; Xia, Y.; Xie, H.; She, M.; Huang, R.; He, L.; Liu, C.; Wang, S.; et al. Establishment and evaluation of a simple size-selective method for exosome enrichment and purification. J. Biomed. Nanotechnol. 2019, 15, 1090-1096. [CrossRef]

4. Cho, Y.J.; Kim, S.Y.; Kim, J.; Choe, E.K.; Kim, S.I.; Shin, H.J. One-step enzymatic synthesis of blue pigments from geniposide for fabric dyeing. Biotechnol. Bioprocess Eng. 2006, 11, 230-234. [CrossRef]

5. Kim, S.J.; Jang, H.G. Characterization and stability of Gardenia jasminoides biotransformed pigment produced in jar fermentor. J. Korean Soc. Food Sci. Nutr. 2005, 34, 880-884.

6. Yang, D.; Zhou, M.; Wei, W.; Zhu, H.; Fan, X. Preparation of a genipin blue from egg protein and genipin. Nat. Prod. Res. 2012, 26, 765-769. [CrossRef]

7. Zhang, J.G.; Shun-Huo, Y.U.; Xian-Xiang, L.I.; Dao-Rong, M.A.; Wei, Z.J. Study on production technology of gardenia blue with two-stage method. Food Sci. 2008, 29, 186-188.

8. Takami, M.; Suzuki, Y. Hydrophobic blue pigment formation from phosphatidylgenipin. J. Nutr. Sci. Vitaminol. 1994, 40, 505-509. [CrossRef] [PubMed]

9. Zhang, F.; Yang, Z.; Gan, C.J. Studies on the stability of hydrophobic gardenia blue. J. Henan Univ. Technol. 2008, $295,26-28$.

10. Butler, M.F.; Ng, Y.F.; Pudney, P.D. Mechanism and kinetics of the crosslinking reaction between biopolymers containing primary amine groups and genipin. J. Polym. Sci. Part A Polym. Chem. 2003, 41, 3941-3953. [CrossRef]

11. Liu, X.; Lou, H. Synthesis of monoterpene alkaloid derivatives from the iridoid glucoside geniposide. Nat. Prod. Res. 2007, 21, 1157-1164. [CrossRef] [PubMed]

12. Ryousuke, T.; Kenichiro, I.; Yoshio, T.; Masahiko, Y.; Takeshi, I.; Nobuharu, M.; Tetsuro, S.; Toshio, Y.; Hiroyuki, I. Studies on the blue pigments produced from genipin and methylamine. II. on the formation mechanisms of brownish-red intermediates leading to the blue pigment formation. Chem. Pharm. Bull. 1994, 42, 1571-1578.

13. Ryousuke, T.; Yoshio, T.; Kenichiro, I.; Ikuo, K.; Masahiko, Y.; Takeshi, I.; Tetsuro, S.; Toshio, Y.; Hiroyuki, I. Studies on the blue pigments produced from genipin and methylamine. I. structures of the brownish-red pigments, intermediates leading to the blue pigments. Chem. Pharm. Bull. 1994, 42, 668-673.

14. Chang, Z.; Jiang, H.; Wu, R.; Zhang, W.; Zeng, H.; Zhang, W.; Li, M. Preparation and analysis of electrochromic properties of poly (3,4 ethylene dioxythiophene). Mater. Express 2020, 10, 1300-1307. [CrossRef]

15. Li, J.C.; Liang, H.Z.; Wu, Z.M.; Li, Y. Investigation on isolation and purifying of gardenia blue pigment with D301 ion exchange resin. Food Sci. Technol. 2005, 7, 50-53.

16. Sheng, K.; Lu, H.; Sun, A.; Wang, Y.; Liu, Y.; Chen, F.; Bian, W.; Li, Y.; Kuang, R.; Sun, D. A naked-eye colorimetric sensor for chloroform. Chin. Chem. Lett. 2019, 30, 895-898. [CrossRef] 
17. Chen, F.; Chen, J.F. Study on the stability of gardenia blue pigment. J. Ningde Norm. Univ. 2013, 25, $236-239$.

18. Fu, X.J.; Dong, X.W.; Jin, H.Z. Study on the stability of gardenia blue pigment. Beverage Fast Frozen Food Ind. 2005, 11, 22-25.

19. Paik, Y.S.; Lee, C.M.; Cho, M.H.; Hahn, T.R. Physical stability of the blue pigments formed from Geniposide of gardenia fruits: Effects of pH, temperature, and light. J. Agric. Food Chem. 2001, 49, 430-432. [CrossRef]

20. Boontawan, P.; Baimark, Y.; Boontawan, A. Fermentation and purification of l-lactic acid by using biorefinery concept to produce a high molecular weight poly(l-lactide) polymer. J. Biobased Mater. Bioenergy 2019, 13, 43-52. [CrossRef]

21. Li, W.H.; Li, C.Y.; Xiong, H.Y.; Liu, Y.; Huang, W.Y.; Ji, G.J.; Jiang, Z.; Tang, H.T.; Pan, Y.M.; Ding, Y.J. Constructing mononuclear palladium catalysts by precoordination/solvothermal polymerization: Recyclable catalyst for regioselective oxidative heck reactions. Angew. Chem. 2019, 58, 2448-2453. [CrossRef]

22. Li, X.; Shi, T.; Li, B.; Chen, X.; Zhang, C.; Guo, Z.; Zhang, Q. Subtractive manufacturing of stable hierarchical micro-nano structures on AA5052 sheet with enhanced water repellence and durable corrosion resistance. Mater. Des. 2019, 183, 108152. [CrossRef]

23. Oda, H. Improving light fastness of natural dye: Photostabilisation of gardenia blue. Color. Technol. 2012, 128, 68-73. [CrossRef]

24. Beck, L.; Gutiérrez, P.C.; Miro, S.; Miserque, F. Ion beam modification of zinc white pigment characterized by ex situ and in situ $\mu$-Raman and XPS. Nucl. Instrum. Methods Phys. Res. 2017, 409, 96-101. [CrossRef]

25. Abdullah, A.; Nurjanah, N.; Reyhan, M. Identification and profiling of active compounds from golden apple snail's egg pigments. J. Pengolah. Has. Perikan. Indones. 2017, 20, 286-295. [CrossRef]

26. Suresh, M.; Renugadevi, B.; Brammavidhya, S.; Iyapparaj, P.; Anantharaman, P. Antibacterial activity of red pigment produced by halolactibacillus alkaliphilus MSRD1-an isolate from seaweed. Appl. Biochem. Biotechnol. 2015, 176, 185-195. [CrossRef] [PubMed]

27. Xu, Y.Z.; Liang, H.Z.; Chen, H.; He, Y.L.; Li, Y. Study on preparation and stability of high color value gardenia blue. Mod. Food Sci. Technol. 2011, 27, 440-443.

28. Kim, S.W.; Sim, G.E.; Ock, J.Y.; Son, J.H.; Hasegawa, T.; Toda, K.; Bae, D.S. Discovery of novel inorganic Mn ${ }^{5+}$-doped sky-blue pigments based on Ca6BaP4O17: Crystal structure, optical and color properties, and color durability. Dyes Pigm. 2017, 139, 344-348. [CrossRef]

29. Liu, S.; Odate, A.; Buscarino, I.; Chou, J.; Frommer, K.; Miller, M.; Scorese, A.; Buzzeo, M.C.; Austin, R.N. An advanced spectroscopy lab that integrates art, commerce, and science as students determine the electronic structure of the common pigment carminic acid. J. Chem. Educ. 2016, 94, 216-220. [CrossRef]

30. Muzzarelli, R.A.A. Genipin-crosslinked chitosan hydrogels as biomedical and pharmaceutical aids. Carbohydr. Polym. 2009, 77, 1-9. [CrossRef] 